\section{$\underset{\text { hommes }}{\text { \& migrations }}$}

\section{Hommes \& migrations}

Revue française de référence sur les dynamiques

migratoires

1335 | 2021

Saisir le murmure du monde

\title{
Mohamed Mbougar Sarr, La plus secrète mémoire des
}

hommes

Paris, Philippe Rey, 2021, 448 p. $22 €$.

\section{Mustapha Harzoune}

\section{(2) OpenEdition}

12 Journals

\section{Édition électronique}

URL : https://journals.openedition.org/hommesmigrations/13463

DOI : 10.4000/hommesmigrations. 13463

ISSN : 2262-3353

\section{Éditeur}

Musée national de l'histoire de l'immigration

\section{Édition imprimée}

Date de publication : 1 octobre 2021

Pagination : 213-214

ISBN : 978-2-919040-59-9

ISSN : 1142-852X

\section{Référence électronique}

Mustapha Harzoune, "Mohamed Mbougar Sarr, La plus secrète mémoire des hommes ", Hommes \& migrations [En ligne], 1335 | 2021, mis en ligne le 01 octobre 2021, consulté le 28 février 2022. URL http://journals.openedition.org/hommesmigrations/13463; DOI : https://doi.org/10.4000/ hommesmigrations. 13463 


\section{Livres}

\section{La plus secrète mémoire des hommes}

Mohamed Mbougar Sarr, Paris, Philippe Rey, 2021, 448 p. $22 €$.

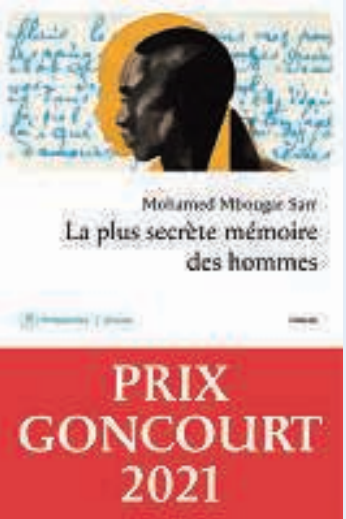

« (...) méfiez-vous, vous écrivains et intellectuels africains, de certaines reconnaissances. Il arrivera bien sûr que la France bourgeoise, pour avoir bonne conscience, consacre l'un de vous, et l'on voit parfois un Africain qui réussit ou qui est érigé en modèle. Mais au fond, crois-moi, vous êtes et resterez des étrangers, quelle que soit la valeur de vos œuvres. Vous n'êtes pas d'ici. » À l'heure où Mbougar Sarr vient d'être gratifié du Goncourt 2021, faut-il prendre à la lettre ces mots prononcés par un traducteur et ami du narrateur, lui-même écrivain africain à Paris. Le propos serait, aujourd'hui, malvenu, non? Par ailleurs, son excès en circonscrit d'emblée la portée. Pour autant, il a le mérite de (re)poser la question des ambiguïtés de la réception en France des auteurs francophones, africains notamment - du nord au sud du Sahara. Tel est l'un des objets de La plus secrète mémoire des hommes.

Mbougar Sarr (31 ans) n'est pas un inconnu du Musée national de l'histoire de l'immigration. Son Silence du Chœur (Présence africaine, 2017) a reçu le prix littéraire du Palais en 2017. Il avait alors été encensé comme étant LE roman attendu sur la question des réfugiés, de l'hospitalité ou du rejet d'un groupe de demandeurs d'asile débarqués dans un village sicilien. Une performance littéraire - et politique - qui montrait, malgré les difficultés et les obstacles, la communauté de destin qui lie les uns et les autres. Et déjà, la force de la littérature.

Sur ce point, La plus secrète mémoire des hommes, poursuit et approfondit Le Silence du Chøur où déjà il était dit que "le récit relate» et « relie». Ainsi est-il encore et toujours question du sens de la littérature. Tout y tourne autour d'un livre et d'un auteur mystérieux: T.C. Elimane dont le seul ouvrage publié - Le Labyrinthe de l'inhumain - raconte l'histoire d'un «Roi sanguinaire, prêt à commettre le Mal absolu pour obtenir le Pouvoir, mais qui découvre que même les voies du Mal absolu le ramènent à l'Humanité ». Il n'est pas certain que le résumé enflamme. D'ailleurs, mieux vaut éviter « de dire de quoi parle un grand livre. Ou, si tu le fais, voici la seule réponse possible: rien ». Car il y a un "piège » à " vouloir dire de quoi parle un livre dont tu sens qu'il est grand. Ce piège est celui que l'opinion te tend. Les gens veulent qu'un livre parle nécessairement de quelque chose. » Un grand livre ne se raconte pas. Un grand livre traine ses zones d'ombres, de mystères et d'ambiguïtés. Un grand livre se refuse aux colliers, fussent-ils d'or, comme aux grilles de lecture rouillées. Comme, en apparence, cet Elimane - personnage inspiré par l'écrivain Yambo Ouologuem, né en 1940 au Mali et qui reçut le prix Renaudot en 1968 pour son premier roman, Le Devoir de violence (Seuil).

À peine débarqué à Paris, le brillantissime Elimane fait paraître, en 1938, son roman qui déclenchera polémiques et brouhahas dans le landernau parisien. Accusé (à raison) par les uns de plagiats, ou de n'être qu'un «barbare »; il est encensé par d'autres qui l'affublent, allez savoir pourquoi, du titre de 
« Rimbaud nègre » pour louer son talent! Elimane devient un phénomène... de foire, des colonies, d'Afrique, un singe savant, un sauvage mal dégrossi, l'exotique de bon aloi, un prétexte, un motif, une cause, une cible, une justification... tout sauf un écrivain et son écriture. Pour l'intéressé, personne n'a pris le temps de lire son roman. Ce qui est un «pêché »! Lui, qui aspirait à la qualité d'écrivain, se voit ravalé au statut de «phénomène médiatique ». Dès lors, il s'enferme dans le silence, refuse de se justifier, devient introuvable. Ainsi commence la légende Elimane; le mystère Elimane et son livre, sur lequel viendront buter la journaliste Brigitte Bollème, ses éditeurs et amis, Thérèse Jacob et Charles Ellenstein et deux générations d'écrivains noirs. Il y a d'abord le narrateur et déjà « prometteur » Diégane Latyr Faye. Siga D., la soixantaine, "l'ange noir de la littérature sénégalaise » dont chacun des livres provoque un scandale. Elle est la cousine d'Elimane. Musimbwa est un écrivain congolais reconnu. Sa lecture du Labyrinthe de l'inhumain le bouleverse au point qu'il quitte Paris et rentre au pays. Sans oublier la poétesse haïtienne, qui fut, au temps de l'exil sud-américain, l'amante d'Elimane.

La quête devient vite pour les uns et pour les autres une obsession, un cauchemar où se mêlent tourment et crainte. Car le mystère demeure si épais qu'on en arrive à prêter à cet Elimane quelques pouvoirs surnaturels, un petit diable de la magie noire par son oncle héritée...

Le roman prend alors des allures d'enquête consistant à suivre tenter de suivre - la trace d'Elimane sur près d'un siècle d'histoire collective et individuelle, à chercher un sens à son roman, à remonter le fil d'un récit qui trouve son origine dans un lointain village sénégalais et une famille déchirée, au temps du colonialisme impératif. Ici sont nés Ousseynou et Assane Koumakh, les deux jumeaux. Non contents d'aimer la même et belle Mossane, la rivalité gémellaire symbolise aussi les conflits politiques en cours et à venir. Tandis qu'Assane est envoyé à l'école des Blancs, "vers le monde extérieur », Ousseynou lui, est chargé de protéger la tradition. Assane, le "petit Noir blanc» partira à la guerre de 1914, pour défendre «la mère patrie », Ousseynou restera au village: il y recueille Mossane devenue l'épouse d'Assane et élève, comme oncle, Elimane, le fils d'Assane et de Mossane, né en 1915. Assane ne reviendra pas du front. Ousseynou prendra soin de la mère et de l'enfant jusqu'à la mort de l'une et... le départ de l'autre. "Les Blancs sont arrivés, et certains de nos plus valeureux fils sont devenus fous. Fous à lier. Fous d'amour pour eux, leurs maîtres. Assane et Elimane font partie de ces fous. » L'école, " c'était une brèche qui s'ouvrait dans notre monde, et on ne savait pas encore ce qui pourrait entrer par-là, ni ce qui pouvait en sortir. » Une chose semble sûre: "L'épine est dans sa chair et il est impossible de la retirer sans mourir. ( ...) cette épine-là fait désormais partie de notre grande blessure, c'est-à-dire de notre vie. »

Roman protéiforme, polyphonique, à cheval sur plusieurs continents (l'Afrique, l'Europe, l'Amérique latine) et plusieurs périodes (du premier âge de la colonisation jusqu'au fleuve détourné de l'indépendance, de la Première à la Seconde guerre mondiale, de l'entre-deux guerres à la résistance, d'exil, ceux de Gombrowicz ou de Sábato, des années 80 en France aux mobilisations sans lendemain à Dakar ou à Alger).

Le style est fiévreux, incandescent, la narration est étouffante: qui est Elimane? De quels pouvoirs (maléfiques) est-il doté? - «J'ai senti son souffle sur ma nuque, son souffle surgi d'entre les morts » dit Siga D. Étouffante et touffue: le lecteur avance, à l'aveugle, se perd, emberlificote raison et émotion, au gré des événements, des circonstances et des thèmes avec au centre la question du sens de la littérature dans l'Histoire et chez les hommes; "Nous ne pensions pas du tout qu'elle sauverait le monde; nous pensions en revanche qu'elle était le seul moyen de ne pas s'en sauver. » Et il y a ces questions annexes, conjoncturelles, historiques et politiques: l'imprimatur de Paris, du centre, donné à telle œuvre ou écrivain des marges; les commentaires qui ne valent pas lectures, le « Ghetto » littéraire de la diaspora, les « négreries» de l'exotisme complaisant des anciens, les pièges de l'universalisme - "Arrachez les derniers lambeaux de l'ère coloniale et n'attendez rien! Au feu toutes ces vieilleries! À la braise, à la cendre, à la mort! Écrivez au pétrole! »-, « l'incontinence littéraire » de l'époque, les équivoques du statut des écrivains africains dans le champ littéraire français, chantres de l'« ambiguité culturelle», " bâtards civilisationnels » ou témoins aliénés de la destruction d'un monde.

Elimane n'a pas plagié les grands auteurs blancs. Il a voulu rendre hommage à toute la littérature des siècles qui l'ont précédé. Dans «ce qui était une longue référence (...) personne n'a vu qu'il était riche avant d'avoir emprunté quoi que ce soit. ». Elimane, Madag l'Africain!, a tenté, par son récit de « relater», autrement, et de « relier», autrement. Mais il n'était pas d'ici. Lui.

Mustapha Harzoune 